Table 1. Baseline parameters and adverse events

\begin{tabular}{|c|c|c|c|c|c|}
\hline & $\begin{array}{l}\mathrm{GOL} \\
\mathrm{n}=81\end{array}$ & $\begin{array}{c}\text { alt. TNFi } \\
\mathrm{n}=162\end{array}$ & $\begin{array}{l}\text { MTX } \\
n=81\end{array}$ & $\begin{array}{l}\text { p-value } \infty \\
\text { GOL vs alt. } \\
\text { TNFi }\end{array}$ & $\begin{array}{c}\text { p-value } \infty \\
\text { GOL vs } \\
\text { MTX }\end{array}$ \\
\hline Gender female ${ }^{\circ}$ & $67(83)$ & $127(78)$ & $64(79)$ & 0.5 & 0.7 \\
\hline Disease duration (yrs) & $7.1 \pm 4.3$ & $4.3 \pm 3.7$ & $1.2 \pm 2.1$ & $<0.0001$ & $<0.0001$ \\
\hline RF neg. Polyarthritis ${ }^{\circ}$ & $40(49)$ & $79(49)$ & $50(62)$ & 1.0 & 0.15 \\
\hline RF pos. Polyarthritis ${ }^{\circ}$ & $8(10)$ & $22(14)$ & $16(20)$ & 0.5 & 0.1 \\
\hline Extended Oligoarthritis ${ }^{\circ}$ & $30(37)$ & $54(33)$ & $13(16)$ & 0.6 & 0.004 \\
\hline Psoriatic arthritis ${ }^{\circ}$ & $3(4)$ & $7(4)$ & $2(3)$ & $1.0 / 1.0$ & 1.0 \\
\hline Pretreatment bDMARD ${ }^{\circ}$ & $68(84.0)$ & 35 (21.6) & 0 & $<0.0001$ & $<0.0001$ \\
\hline $\begin{array}{l}\text { Concomitant systemic } \\
\text { steroids, } \mathrm{n}(\%)\end{array}$ & $13(16)$ & $38(24)$ & $39(48)$ & 0.2 & $<0.0001$ \\
\hline Active joint count \# & $4.6 \pm 4.8$ & $4.9 \pm 5.7$ & $9.6 \pm 6.5$ & 0.4 & $<0.0001$ \\
\hline CHAQ DI \# & $0.4 \pm 0.5$ & $0.5 \pm 0.5$ & $0.6 \pm 0.6$ & 0.1 & 0.02 \\
\hline JADAS10 \# & $11.6 \pm 6.2$ & $12.1 \pm 6.1$ & $16.8 \pm 5.3$ & 0.6 & $<0.0001$ \\
\hline $\mathrm{AE}$ * & $\begin{array}{l}91(107.4 \\
88-132)\end{array}$ & $\begin{array}{l}213(88.7 \\
78-101)\end{array}$ & $\begin{array}{c}113(119.8 \\
100-144)\end{array}$ & 0.1 & 0.4 \\
\hline $\mathrm{SAE}^{*}$ & $4(4.7 ; 2-13)$ & $7(2.9 ; 1-6)$ & $1(1.1 ; 0.1-8)$ & 0.4 & 0.2 \\
\hline Serious infections * & $1(1.2 ; 0.2-8.4)$ & $2(0.8 ; 0.2-3.3)$ & 0 & 0.7 & n.a. \\
\hline Autoimmune process (\%) & $2(2.4)$ & $3(1.9)$ & $1(1.2)$ & 1.0 & 1.0 \\
\hline $\begin{array}{l}\text { Patients with uveitis new } \\
\text { manifestation after } \\
\text { study entry * }\end{array}$ & $1(1.2 ; 0.2-8)$ & $2(0.8 ; 0.5-3)$ & 0 & 0.7 & n.a. \\
\hline $\begin{array}{l}\text { Patients with uveitis flare } \\
\text { events with preexisting } \\
\text { uveitis at baseline* }\end{array}$ & $6(7.1 ; 3-16)$ & 0 & 0 & n.a. & n.a. \\
\hline
\end{tabular}

childhood health assessment questionnaire disability index ( $\mathrm{CHAQ} \mathrm{Di}$ ), juvenile arthritis disease activity index (JADAS), adverse event (AE), patient year (PY), ${ }^{\circ} \mathrm{n}(\%)$, \# mean (SD), * $\mathrm{n}$ (rate/100PY; 95\% Cl), Golimumab (GOL), alternative tumor necrosis factor inhibitor (alt. TNFi), methotrexate (MTX), $\infty$ by t-test or $\chi 2$-test as appropriate.

None declared, Daniel Windschall: None declared, Nils Onken: None declared, Markus Hufnagel: None declared, Dirk Foell: None declared, Normi Brueck: None declared, Prassad Thomas Oommen: None declared, Frank Dressler: None declared, Astrid Helling-Bakki: None declared, Gerd Horneff Speakers bureau: MSD.

DOI: 10.1136/annrheumdis-2021-eular.2145

\section{POS0076 \\ S100A8/A9 AND S100A12 AS POTENTIAL PREDICTIVE BIOMARKERS OF ABATACEPT RESPONSE IN POLYARTICULAR JUVENILE IDIOPATHIC ARTHRITIS}

N. Ruperto $^{1}$, G. Schulert ${ }^{2}$, A. Sproles ${ }^{2,3}$, S. Thornton ${ }^{2,3}$, G. Vega Cornejo ${ }^{4}$, J. Anton ${ }^{5}$, R. Cuttica ${ }^{6}$, M. Henrickson ${ }^{2}$, I. Foeldvari ${ }^{7}$, D. Kingsbury ${ }^{8}$, M. Askelson ${ }^{9}$, J. Liu ${ }^{10}$, S. Mukherjee ${ }^{11}$, R. Wong ${ }^{12}$, D. J. Lovell ${ }^{13}$, A. Martini $^{14}$, A. Grom ${ }^{2}, \mathrm{H}$. Brunner ${ }^{2}$ on behalf of Pediatric Rheumatology Collaborative Study Group (PRCSG) and Paediatric Rheumatology International Trials Organisation (PRINTO). ${ }^{1}$ IRCCS Istituto Giannina Gaslini, Clinica Pediatrica e Reumatologia, Genova, Italy; ${ }^{2}$ Cincinnati Children's Hospital Medical Center, Division of Rheumatology, Cincinnati, United States of America; ${ }^{3}$ University of Cincinnati College of Medicine, Department of Pediatrics, Cincinnati, United States of America; ${ }^{4}$ Hospital México Americano, CREA, Guadalajara, Mexico; ${ }^{5} \mathrm{Hospital}$ Sant Joan de Déu, Division of Pediatric Rheumatology, Barcelona, Spain; ${ }^{6}$ Hospital General de Niños Pedro de Elizalde, Pediatric Rheumatology, Buenos Aires, Argentina; ${ }^{7}$ Hamburg Centre for Pediatric and Adolescent Rheumatology, Schön Klinik Hamburg Eilbek, N/A, Hamburg, Germany; ${ }^{8}$ Randall Children's Hospital at Legacy Emanuel, Division of Rheumatology, Portland, United States of America; ${ }^{9}$ Bristol Myers Squibb, Global Biometric Sciences, Princeton, United States of America; ${ }^{10}$ Bristol Myers Squibb, Translational Medicine, Princeton, United States of America; ${ }^{11}$ Bristol Myers Squibb (at the time of analysis), Translational Medicine, Princeton, United States of America; ${ }^{12}$ Bristol Myers Squibb, Immunology and Fibrosis, Princeton, United States of America; ${ }^{13}$ Cincinnati Children's Hospital Medical Center, Department of Pediatrics, Division of Rheumatology, Cincinnati, United States of America; ${ }^{14}$ University of Genoa, N/A, Genoa, Italy

Background: The calcium-binding proteins S100A8/A9 (calprotectin) and S100A12 (extracellular newly identified receptor for advanced glycation end-products binding protein [EN-RAGE]) are involved in multiple signalling pathways to mediate inflammation, can be secreted by activated monocytes/macrophages and exhibit cytokine-like extracellular functions. Circulating levels of these proteins have been associated with disease and clinical responses in systemic juvenile idiopathic arthritis (sJIA), including treatment response. ${ }^{1}$ Studies suggest that serum S100A8/A9 and S100A12, which are released at inflammation sites, are more specific biomarkers of local inflammation (e.g. in the synovium) than systemic biomarkers such as CRP and ESR., ${ }^{2,3}$

Objectives: To investigate if baseline S100A8/A9 and S100A12 predict clinical response to abatacept treatment in polyarticular JIA (pJIA), and to assess whether changes from baseline in S100A8/A9 or S100A12 can be better prognostic markers for response to abatacept treatment than CRP in pJIA

Methods: Data are from a phase III trial of SC abatacept for the treatment of pJIA (NCT01844518). ${ }^{4}$ This 24-month, single-arm, open-label, international, multicentre, two-part study included male and female patients with pJIA aged 2-17 years. This analysis examined the correlation between biomarkers (S100A8/A9, S100A12 and high-sensitivity CRP [hsCRP]) and disease activity (measured using Juvenile Arthritis Disease Activity Score [JADAS]) at baseline, baseline biomarker values as predictors of future treatment response (ACR and JADAS endpoints), and the correlation between change from baseline in biomarker values and treatment response at Day 113.

Results: Of 219 total patients, 158 (72\%) had S100A8/A9 values and 155 (71\%) had S100A12 values at baseline. Median S100A8/A9 and S100A12 values were $3295 \mathrm{ng} / \mathrm{mL}$ (normal range, $716-3004 \mathrm{ng} / \mathrm{mL}$ ) and $176 \mathrm{ng} / \mathrm{mL}$ (normal range, 32 $385 \mathrm{ng} / \mathrm{mL}$ ), respectively. S100A8/A9, S100A12 and hsCRP (median $0.20 \mathrm{mg} /$ $\mathrm{dL}$; normal $\leq 0.6 \mathrm{mg} / \mathrm{dL}$ ) had a low-to-moderate but significant association with disease activity at baseline; coefficients for associations between JADAS71-CRP low disease activity (LDA) and the biomarkers S100A8/A9, S100A12 and hsCRP were $0.23(p=0.0038), 0.16(p=0.0448)$ and $0.26(p=0.0001)$, respectively. Baseline S100A8/A9 level above the median was associated with lower odds of ACR100 at Day $113(p=0.0052)$. Figure 1 shows the associations of baseline biomarker values with Day 113 ACR and JADAS scores in the overall population. Baseline S100A8/A9 or S100A12 did not significantly influence ACR50 or ACR70 responses at Day 113, but high baseline values were associated with reduced odds of ACR90 ( $p=0.01), A C R 100(p=0.005)$, ACR-inactive disease (ID) $(p=0.0001)$, and JADAS71-CRP (LDA) $(p=0.02)$. By Day 477, elevated baseline S100A12 was still significantly associated with lower odds of ACR100 overall $(0.467 ; p=0.0248)$ but baseline $\mathrm{S} 100 \mathrm{~A} 8 / \mathrm{A} 9$ was not; at Day 645 , neither was significantly associated with ACR100 response. At Day 113, changes from baseline in S100A8/A9 and S100A12 were correlated with ACR100 (coefficients of 0.22 $[p=0.0082]$ and $0.26[p=0.0015]$, respectively) and with ACR-ID $(0.22[p=0.0067]$ and 0.26 [ $p=0.0014]$, respectively); change in hsCRP was not significantly correlated with disease response.

Conclusion: S100A8/A9 and S100A12 may serve as prognostic biomarkers to predict response to abatacept treatment at Day 113. Changes from baseline S100A8/A9 and S100A12 levels were more highly correlated with efficacy outcomes including ACR100 and ACR-ID at Day 113 compared with hsCRP.

REFERENCES:

[1] Aljaberi N, et al. Pediatr Rheumatol Online J 2020;18:7.

[2] Hammer H, et al. Arthritis Res Ther 2011;13:R178.

[3] Nordal HH, et al. BMC Musculoskelet Disord 2014;15:335.

[4] Brunner H, et al. Arthritis Rheumatol 2018;70:1144-1154.

Figure 1. Effect of baseline S100AB/A9 or S100A12 level on efficacy response at Day 113 in the overall population

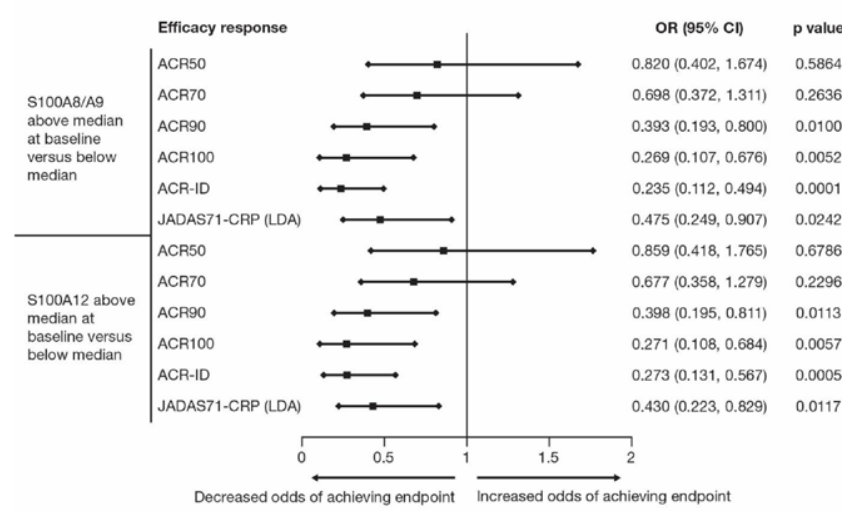

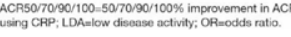

Acknowledgements: Professional medical writing and editorial assistance was provided by Rob Coover, MPH, at Caudex and was funded by Bristol Myers Squibb.

Disclosure of Interests: Nicolino Ruperto Speakers bureau: NR has received honoraria for consultancies or speaker bureaus ( $<10.000$ USD each) from the following pharmaceutical companies in the past 3 years: Ablynx, Astrazeneca-Medimmune, Bayer, Biogen, Boehringer, Bristol Myers Squibb, Celgene, Eli Lilly, EMD Serono, GlaxoSmithKline, Hoffmann-La Roche, Janssen Merck, Novartis, Pfizer, R-Pharma, Sinergie, Sobi and UCB, Consultant of NR has received honoraria for consultancies or speaker bureaus $(<10.000$ USD each) from the following pharmaceutical companies in the past 3 years: Ablynx, Astrazeneca-Medimmune, Bayer, Biogen, Boehringer, Bristol Myers Squibb, Celgene, Eli Lilly, EMD Serono, GlaxoSmithKline, Hoffmann-La Roche, Janssen, Merck, Novartis, Pfizer, R-Pharma, Sinergie, Sobi and UCB, Grant/ 
research support from: The IRCCS Istituto Giannina Gaslini (IGG), where NR works as full-time public employee has received contributions (>10.000 USD each) from the following industries in the last 3 years: Bristol Myers Squibb, Eli Lilly, F Hoffmann-La Roche, GlaxoSmithKline, Janssen, Novartis, Pfizer, Sobi. This funding has been reinvested for the research activities of the hospital in a fully independent manner, without any commitment with third parties., Grant Schulert Speakers bureau: Novartis, Consultant of: SOBI, Alyssa Sproles: None declared, Sherry Thornton: None declared, Gabriel Vega Cornejo Speakers bureau: AbbVie, Grant/research support from: Bristol Myers Squibb, Eli Lilly, Janssen, Parexel, Sanofi, Jordi Anton Speakers bureau: AbbVie, Gebro, GlaxoSmithKline, Novartis, Pfizer, Roche, Sobi, Consultant of: AbbVie, Gebro, GlaxoSmithKline, Novartis, Pfizer, Roche, Sobi, Grant/research support from: AbbVie, Amgen, Gebro, GlaxoSmithKline, Lilly, Novartis, Novimmune, Pfizer, Roche, Sanofi, Sobi, Ruben Cuttica Speakers bureau: AbbVie, Bristol Myers Squibb, GlaxoSmithKline, Lilly, Novartis, Pfizer, Roche, UCB, Paid instructor for: AbbVie, Novartis, Pfizer, Roche, Consultant of: AbbVie, Bristol Myers Squibb, GlaxoSmithKline, Lilly, Novartis, Pfizer, Roche, UCB, Michael Henrickson: None declared, Ivan Foeldvari Consultant of: Bristol Myers Squibb, Gilead, Hexal, MEDAC, Novartis, Pfizer, Sanofi, Daniel Kingsbury Consultant of: Pfizer, Margarita Askelson Consultant of: Currently working for Syneos Health providing services to Bristol Myers Squibb, Jinqi Liu Shareholder of: Bristol Myers Squibb, Employee of: Bristol Myers Squibb, Sumanta Mukherjee Shareholder of: Bristol Myers Squibb, GlaxoSmithKline, Employee of: Bristol Myers Squibb, GlaxoSmithKline, Robert Wong Shareholder of: Bristol Myers Squibb, Employee of: Bristol Myers Squibb, Daniel J Lovell Speakers bureau: Genentech, Wyeth Pharm, Consultant of: Abbott, Amgen, AstraZeneca, Boehringer Ingelheim, Celgene, GlaxoSmithKline, Hoffman-La Roche, Novartis, Pfizer, Regeneron, Takeda, UBC, Wyeth Pharma, Xoma, Alberto Martini Speakers bureau: AbbVie, Novartis, Consultant of: AbbVie, Eli Lilly, EMD Serono, Idorsia, Janssen, Novartis, Pfizer, Alexei Grom Consultant of: AB2Bio, Novartis, Sobi (Novlmmune), Grant/research support from: AB2Bio, Novartis, Sobi (Novlmmune), Hermine Brunner Speakers bureau: GlaxoSmithKline, Novartis, Pfizer, Roche, Paid instructor for: Novartis, Pfizer (funds go to CCHMC/employer), Consultant of: Boehringer Ingelheim, Bristol Myers Squibb, GlaxoSmithKline, Janssen, Merck, Novartis, Pfizer, Roche, UCB (funds go to CCHMC/employer), Grant/research support from: Bristol Myers Squibb, Pfizer (funds go to CCHMC/ employer).

DOI: 10.1136/annrheumdis-2021-eular.1081

\section{POS0077 PHYSICAL ACTIVITY AND SPORT PARTICIPATION A COMPARISON BETWEEN CHILDREN AND ADOLESCENTS WITH JUVENILE IDIOPATHIC ARTHRITIS (JIA) AND THE GERMAN GENERAL POPULATION}

F. Milatz $^{1}$, M. Niewerth ${ }^{1}$, J. Klotsche ${ }^{1}$, J. Hörstermann ${ }^{1}$, S. Hansmann ${ }^{2}$, T. Kallinich ${ }^{3}$, C. Rietschel ${ }^{4}$, R. Trauzeddel ${ }^{5}$, J. Peitz ${ }^{6}$, M. Hartmann ${ }^{7}$, H. Girschick ${ }^{8}$, K. Minden ${ }^{1,9}$. 'German Rheumatism Research Centre, Epidemiology and Health Care Research, Berlin, Germany; ${ }^{2}$ University Children's Hospital Tuebingen, Center for Pediatric Rheumatology, Autoinflammation Reference Centre Tuebingen (arcT), Tuebingen, Germany; ${ }^{3}$ Charité University Medicine Berlin, Department of Pediatric Pneumology and Immunology, Berlin, Germany; ${ }^{4}$ Clementine Children's Hospital, Rheumatology for Children and Adolescents, Frankfurt/Main, Germany; ${ }^{5}$ Helios Klinik Berlin-Buch, Department of Paediatrics, Berlin, Germany; ${ }^{6}$ Asklepios Clinic, Paediatric Rheumatology Centre, Sankt Augustin, Germany; ${ }^{7}$ German Center for Paediatric and Adolescent Rheumatology, Motion Analysis, GarmischPartenkirchen, Germany; ${ }^{8}$ Vivantes Hospital im Friedrichshain, Children's Hospital, Berlin, Germany; ${ }^{9}$ Charité University Medicine Berlin, Department of Rheumatology and Clinical Immunology, Berlin, Germany

Background: Physical activity (PA), including sport participation is essential for children throughout their growth and maturation. It improves physiological and psychosocial health and limits the risk of developing metabolic disorders. The beneficial effect of PA specifically in patients with JIA has also been linked to its potential regulatory effect on the balance between pro- and anti-inflammatory responses [1].

Objectives: The study aimed i) to quantify the frequency of PA and participation in (organised) sports compared to the general population, ii) to determine self-reported reasons for not practicing sports, and iii) to identify clinical parameters associated with non-participation in sports.

Methods: Data from children and adolescents with JIA recorded in the National Paediatric Rheumatological Database (NPRD) in the year 2019 were considered for the analyses. In accordance with the methodology used in the general population survey (KIGGS) [2], achievement of the WHO recommendations on PA for at least 60 minutes per day as well as sport-related data were determined on the basis of self-reported outcomes in individuals aged 3 to 17 years. In order to compare PA-related data with the general population, a sex- and age-matched sample was drawn. A logistic regression model was used to explore the association between non-participation in sports and patients' clinical outcomes.

Results: Data of 5.333 matched-pairs (mean age $11.0 \pm 4.3$ years, female $67 \%$, patients' disease duration $4.8 \pm 3.8$ years, persistent oligoarthritis $43 \%$ ) were available for evaluation. Almost $38 \%$ of patients aged 3 to 17 years met the recommended PA amount ( $76 \%$ aged 3 to $6 ; 48 \%$ aged 7 to $10 ; 30 \%$ aged 11 to 13 $15 \%$ aged 14 to 17$)$. In matched controls, $21 \%$ fulfilled the WHO recommendations on PA ( $41 \%$ aged 3 to $6 ; 23 \%$ aged 7 to $10 ; 17 \%$ aged 11 to $13 ; 10 \%$ aged 14 to 17). Largest differences across JIA categories were found in persistent oligoarthritis (43\%) and enthesitis-related arthritis (22\%). $64 \%$ of patients and $74 \%$ of controls reported participating in sports, of which $72 \%$ of patients and $58 \%$ of controls stating to participate in a formally organised way. In both groups, boys indicated organised sports participation more often than girls. Among those who declared not participating in sports, "no interest" (patients $27 \%$ vs. controls $29 \%$ ), "no suitable offer nearby" (patients $25 \%$ vs. controls $31 \%$ ), "health restrictions" (patients $22 \%$ vs. controls $4 \%$ ) and "no time" (patients $15 \%$ vs. controls $23 \%$ ) were the most frequently mentioned reasons (multiple responses possible). CJADAS-10 $(\mathrm{OR}=1.02,95 \% \mathrm{Cl}=1.00-1.04), \mathrm{CHAQ}(\mathrm{OR}=1.79,95 \% \mathrm{Cl}=1.50-$ 2.14), DMARD use $(\mathrm{OR}=1.32,95 \% \mathrm{Cl}=1.15-1.53)$ and disease duration (OR $=0.97,95 \% \mathrm{Cl}=0.95-0.99)$ were significantly associated with non-participation in sports.

Conclusion: Based on self-reported data, children and adolescents with JIA meet the WHO recommendation on PA more often than general population controls. Patients are less frequently engaged in sports, but more often involved in formally organised forms. In order to bring joyful, interesting PA opportunities in line with WHO recommendations, further components (e.g. intensity), facilitators and barriers to PA and sports need to be addressed in the future while controlling for JADAS and CHAQ.

\section{REFERENCES:}

[1] Rochette E et al. JIA and physical activity: possible inflammatory and immune modulation and tracks for interventions in young populations. Autoimmun Rev 2015;14:726-734.

[2] Finger JD et al. Körperliche Aktivität von Kindern und Jugendlichen in Deutschland - Querschnittergebnisse aus KiGGS Welle 2 und Trends. Jour nal of Health Monitoring 2018;3:24-31.

Acknowledgements: The National Paediatric Rheumatological Database has been funded by AbbVie, Chugai, Novartis and GSK.

Disclosure of Interests: Florian Milatz: None declared, Martina Niewerth: None declared, Jens Klotsche: None declared, Jana Hörstermann: None declared, Sandra Hansmann: None declared, Tilmann Kallinich: None declared, Christoph Rietschel: None declared, Ralf Trauzeddel: None declared, Joachim Peitz: None declared, Matthias Hartmann: None declared, Hermann Girschick: None declared, Kirsten Minden Speakers bureau: Pfizer, AbbVie, Consultant of: Novartis.

DOI: 10.1136/annrheumdis-2021-eular.2356

\section{POS0078 \\ CROSS-SECTIONAL ANALYSIS OF INTERFERON SIGNATURE IN PEDIATRIC SYSTEMIC LUPUS ERYTHEMATOSUS}

R. Raupov ${ }^{1}$, E. Suspitsin ${ }^{2,3}$, E. Kalashnikova ${ }^{1}$, N. Lybimova ${ }^{4}$, E. Kuchinskaya ${ }^{4}$, R. Mulkidzhan ${ }^{2}$, A. Kosmin ${ }^{2}$, M. Kostik ${ }^{1,4}$. ${ }^{1}$ Saint-Petersburg State Pediatric Medical University, Department of Hospital Pediatrics, Saint-Petersburg, Russian Federation; ${ }^{2}$ N.N.Petrov Institute of Oncology, Molecular diagnostics, Saint-Petersburg, Russian Federation; ${ }^{3}$ Saint-Petersburg State Pediatric Medical University, Department of Medical Genetics, Saint-Petersburg, Russian Federation; ${ }^{4}$ Almazov National Medical Research Centre, Pediatrics, SaintPetersburg, Russian Federation

Background: the role of interferon pathways in the pathogenesis of systemic lupus erythematosus (SLE) has been proven over the past years. Existing data suggest that interferon score (IFN I score) may serve as a useful marker of disease activity and patient clinical characteristics.

Objectives: to compare characteristics of pediatric SLE patients with high and normal IFN I score.

Methods: 40 SLE patients (33 girls, 7 boys) under 18 years old were included in the cross-sectional study. In all cases the diagnosis was made using Systemic Lupus International Collaborating Clinics (SLICC) classification criteria. The data on clinical manifestations, disease activity by SLEDAI and ECLAM, laboratory findings in the onset of the disease and at the moment of interferon signature assessment were evaluated. Interferon signature was assessed by real-time PCR quantitation of 5 IFN I-regulated transcripts; median expression of $\geq 2$ was considered as a threshold. The patients were divided into 2 groups depending on the level of interferon score: high (group1, $n=31$ ) and normal (group2, $n=9$ ).

Results: The mean age of the disease onset was $12(9.5 ; 14.0)$ years. The most common symptoms were skin lesions $(85 \%)$, arthritis $(67.5 \%)$, fever $(55 \%)$ mucosa (45\%), CNS (37.5\%) and kidney (30\%) involvement. Anemia, leukopenia and thrombocytopenia were observed in $62.5 \%, 27.5 \%$ and $50 \%$ of cases 